\title{
From admission to inclusion: Book review: The Privileged Poor: How Elite Colleges Are Failing Disadvantaged Students by Anthony Abraham Jack. Harvard University Press, 2019
}

\author{
Zsuzsanna Sütő1 \\ https://doi.org/10.51624/SzocSzemle.2021.3.8 \\ Manuscript received: 11 September 2020. \\ Revised manuscript received: 23 December 2020. \\ Acceptance of manuscript for publication: 6 January 2021.
}

The question of social mobility is one of the oldest of social sciences, which scrutinizes the question of how societies are structured, while social changes are also focal points of sociology. We can characterise a society by examining its uniqueness throughout the nexus of social layers, and the relative openness of various social strata, which eventually indicate how a society is capable to adapt to changes. Social mobility is one's movement from one societal group or class to another. Anthony Abraham Jack's book, The Privileged Poor. How Elite Colleges Are Failing Disadvantaged Students examines an important segment of social mobility in American society. It discusses what role the educational system plays in social mobility in the United States of America given that in many cases elite colleges represent the first step to reach higher social status. The author also emphasises the responsibility of institutions, and scrutinises how their cultural and academic milieu affects one's upward social mobility. Anthony Abraham Jack's central premise looks at how first-generation, low-income, disadvantaged students navigate campus life at elite universities in the United States.

On the basis of the Introduction of the book non-loan financial aid policy was introduced 20 years ago at public universities in America. The goal was to increase students' social economic diversity in order to reduce social inequality. As a result, more poor or disadvantaged students enrolled at universities but this was just a starting point, since most of the student body stayed still affluent. As a consequence, campus life is still dominated by wealthy students, which means students coming from affluent families feel at home, given their previous social and academic

1 Institute for Minority Studies, Research Centre for Social Sciences, Hungarian Academy of Sciences, email: suto.zsuzsanna@tk.hu 
experience, while their poorer peers feel like fish out of water. As a consequence, these disadvantaged students have distanced themselves from their peers and have withdrawn from college communities, resulting in a circumscribed life on campus. Such social undercurrents have been emotionally hard or even traumatic, in diverse ways, for those coming from disadvantageous background in terms of both class and race. Despite being admitted to elite educational institutions, students from poorer backgrounds often feel alienated from student society, and one policy is not enough to solve this apparent social problem.

Jack has examined this dilemma experienced by students coming from disadvantaged backgrounds on the basis of his own lived experiences, which presumably also stimulated this research. Regarding the research process itself, Jack spent more than two years at an elite college, referred to as a 'Renowned University' where he conducted more than 250 hours of interviews with 103 students. The author justified the high number of interviews by reasoning that if students hear other students detailing their experiences themselves, in their own words, then other students would relate to and understand these experiences much better. The researcher managed to register not only the narratives of students, but also analysed how these students could use resources gained in other, earlier experiences to manage their campus lives.

The first result of his research shows that it is not enough to consider social backgrounds in order to get to the root of the problem. The earlier approaches focused on the lack of success amongst poorer students, which was attributed directly to their financial and cultural social backgrounds. In order to better understand the lives of poor students in elite colleges, Jack differentiates two groups of students on the basis of earlier schools: the Privileged Poor and the Double Disadvantaged,. The Privileged Poor had attended high schools with well qualified teachers, topflight facilities, abundant resources and were thus able to share their prior knowledge with other less advantaged students. As a result these students enter college already accustomed to navigating elite academic arenas. This is in contrast with the Double Disadvantaged students, whose former teachers were younger and less experienced, and had to deal more with discipline than teaching. The social fabric of high schools in the case of the Privileged Poor resembles that of elite colleges, so these poor students managed to better adapt to the new institutions. Therefore, the two groups of students had desperate pre-university experiences, but different cultural and social resources to mobilise for navigating campus life. The author illustrates perfectly these two student groups, by the example of two girls who had similar social background (called social twins by the author), but different educational background. Both of them were admitted to colleges, but one of them was more successful in the process of institutional socialization than the other. This why the focus on the crucial role of high schools is important; and this is what I view as key to current research and should be recommended as pivotal for further researchers. 
Another insight of the book is that it emphasises the responsibility of colleges in student success, because the author points out how differently students from different backgrounds make use of university services. For example the Privileged Poor consult with professors more often and they are more active participants of campus culture than the Double Disadvantaged, whose main goal is to score higher points. As a consequence, the Double Disadvantaged students' institutional integration depends on institutional access (admission), but also on the 'implementation' of inclusion, which should guarantee that it really takes place via special integrating programs. That is to say professors and university staff should realise that they need to change their communication, develop a more sensitive attitude towards poor and disadvantaged students, and employ specific programs and methods in order to help them to be more integrated into campus life.

A further significance of the book is that the author interprets the inclusion not only at an institutional level, but also beyond student life and in relation to the labour market. He presupposes that poor or disadvantaged students will likely avoid workplaces where they could potentially experience a feeling of inferiority or being second class citizens.

I must note that the author has described the dilemma of student cohesion in diverse ways with a fine analytic quality, but I would have asked students themselves how to solve this issue, in other words, which way would suit them the best.

Regarding the structure, the book is well-organised and clearly understandable. In the Introduction the author reveals his own experiences, coming from a privilegedpoor background. The next chapter contains three detailed case studies based on students' narratives. The following part sums up the main issues of the research. Additional information is made available in the Appendix. The Notes and Index section contribute to an easier orientation and a deeper understanding.

I absolutely recommend this volume to students of all backgrounds, researchers and policy makers, given that the main message of the book is relevant for all of them. All in all, this book is an excellent example of a well-written, qualitative research which provides a new aspects of the field, in order to better understand key problematic social and educational questions. 